\title{
PENGARUH PERTUMBUHAN PENJUALAN DAN LIKUIDITAS TERHADAP HARGA SAHAM PADA PERUSAHAAN MANUFAKTUR SEKTOR ANEKA INDUSTRI YANG TERDAFTAR DI BURSA EFEK INDONESIA PERIODE 2015- 2019
}

\author{
Veny Mayasari ${ }^{1)}$, Harmoni $^{2)}$
}

${ }^{1}$ Dosen Jurusan Manajemen, Universitas Tridinanti Palembang, Sumatera Selatan, Indonesia

${ }^{2}$ Mahasiswa jurusan Manajemen, Universitas Tridinanti Palembang, Sumatera Selatan, Indonesia

1)Email : veny_mayasari@univ-tridinanti.ac.id,2)Email : harmoniiskandar96@gmail.com

\begin{tabular}{l} 
INFORMASI \\
ARTIKEL \\
\hline Submitted: \\
15/12/2021 \\
Revised: \\
20/12/2021 \\
Accepted: \\
25/12/2021 \\
Online-Published: \\
31/12/2021
\end{tabular}

\section{ABSTRAK}

\begin{abstract}
Harga saham adalah harga yang terbentuk sesuai dengan permintaan dan penawaran di pasar saham dan biasanya berupa harga penutupan atau dikenal dengan istilah close price. Harga saham di pengaruhi banyak faktor baik yang bersifat mikro maupun makro ekonomi. Untuk itu perlu dilakukan penelitian mengenai faktor-faktor yang mempengaruhi harga saham. Tujuan yang hendak dicapai dalan penelitian ini adalah untuk mengetahui seberapa besar pengaruh pertumbuhan penjualan dan likuiditas terhadap harga saham pada perusahaan manufaktur sektor aneka industri yang tedaftar di Bursa Efek Indonesia periode 2015-2019. Teknik pengumpulan data dilakukan dengan dengan dokumen yaitu dengan cara mengunduh laporan keuangan perusahaan manufaktur sektor aneka industri tahun 2015 sampai dengan tahun 2019 kemudian diolah lebih lanjut untuk dijadikansampelpenelitian.Populasidalampenelitianiniberjumlah24perusahaan dan 9 sampel perusahaan manufaktur sektor anekaindustry. Hasil penelitian ini menunjukkan bahwa Nilai Koefisien Determinasi ( $R$ square) sebesar 0,116 atau $11,6 \%$, artinya pengaruh pertumbuhan penjualan $(X 1)$ dan likuiditas (current ratio) (X2) terhadap harga saham $(Y)$ sebesar 11,6\% sedangkan sisanya sebesar 88,4\% dipengaruhi oleh variabel lain yang tidak disebutkan dalam model penelitian ini.Dari hasil statistik juga menunjukan bahwa pertumbuhan penjualan (XI) secara parsial tidak memiliki pengaruh yang signifikan terhadap harga saham (Y), likuiditas (current ratio) (X2) secara parsial memiliki pengaruh yang signifikan terhadap harga saham (Y). Secara simultan pertumbuhan penjualan (XI) dan likuiditas (current ratio) (X2) tidak memiliki pengaruh yang signifikan terhadap hargasaham(Y).Hal ini dapat dibuktikan melalui staistik uji F, dimana nilai F.sig sebesar 0,074(7,4\%) yang berarti nilainya lebih besar dari taraf signifikansi sebesar 0,05 (5\%) maka menerima Ho dan menolakHa.
\end{abstract}

Katakunci: Pertumbuhan penjualan, Likuiditas (Current Ratio) dan Harga Saham

\begin{abstract}
The stock price is the price that is formed according to supply and demand in the stock market and is usually in the form of a closing price or known as the closing price. Stock prices are influenced by many factors, both micro and macroeconomic. For this reason, it is necessary to do research on the factors that affect stock prices. The aim of this research is to find out how much influence sales growth and liquidity have on stock prices in manufacturing companies, various industrial sectors listed on the Indonesia Stock Exchange for the 2015-2019 period. Data collection techniques are carried out with documents, namely by downloading the financial statements of manufacturing companies in the various industrial sectors from 2015 to 2019 and then further processing them to be used as research samples. The population in this study found 24 companies and 9 samples of manufacturing companies in the various industrial sectors. The results of this study indicate that the coefficient of determination ( $R$ square) is 0.116 or $11.6 \%$, meaning that the effect of sales growth $(X 1)$ and liquidity (current ratio) (X2) on stock prices $(Y)$ is $11.6 \%$ while the rest is $88.4 \%$ is influenced by other variables not mentioned in this research model. The statistical results also show that sales growth $(X 1)$ partially has no significant effect on stock prices ( $Y$ ), liquidity (current ratio) (X2) partially has a significant effect on
\end{abstract}


stock prices (Y). Simultaneously, sales growth (X1) and liquidity (current ratio) (X2) have no significant effect on stock prices $(Y)$. This can be proven through the $F$ statistical test, where F. sig $0.074(7.4 \%)$ which means the value is greater than the significance level of $0.05(5 \%)$ then accepts $\mathrm{HO}$ and rejects $\mathrm{Ha}$.

Keywords: Sales Growth, Liquidity (Current Ratio) and Stock Price

\section{A. PENDAHULUAN}

Bursa Efek Indonesia merupakan pasar modal yang ada di Indonesia. Bursa Efek Indonesia memiliki peranan penting diantaranya sebagai sarana bagimasyarakat untuk berinvestasi dan bagi perusahaan BursaEfekIndonesiamembantuuntukmendapa tkantambahanmodaldengancaragopublic,seba gai sarana tambahan modal dengan menerbitkan saham sebagaitandakepemilikannya. Saham merupakan surat berharga berupa kepemilikan. Sektor aneka industri adalah salah satu sektor BEI dan masuk kelompok industri manufaktur yaitu industri yang mengolah bahan baku menjadi barang jadi (produk) atau barang setengah jadi (komponen). Industri manufaktur identik dengan pabrik. Aneka industri memiliki beberapa subsektor yaitu subsektor mesin \& alat berat, subsektor otomotif \& komponennya, subsektor tekstil \& garment, subsektor alas kaki, subsektor kabel dan subsektor elektronika.

Dalam penelitian terdahulu dilakukan oleh Jeany Clarensia et. al. (2011) mengenai "pengaruh likuiditas, profitabilitas, pertumbuhan penjualan dan kebijakan deviden terhadap harga saham (studi empiris pada perusahaan manufaktur yang terdaftar di BEI tahun 2008-2010) didapat Current Ratio (CR) berpengaruh secara signifikan terhadap harga saham. Adapun Santi oktaviani dan Dahlia Komalasarai (2017) mengenai "pengaruh likuiditas, profitabilitas, dan solvabilitas terhadap harga saham (studi kasus pada perusahaan perbankan yang terdaftar di BEI)" didapat Likuiditas tidak berpengaruh secara signifikan terhadap harga saham. Adapun Tita Deitiana (2011) mengenai "pengaruh rasio keuangan, pertumbuhan penjualan dan deviden terhadap harga saham yang didapat likuiditas, dividen dan pertumbuhan penjualan tidak berpengaruh terhadap harga saham.

Berdasarkan uraian di atas maka peneliti tertarik mengambil judul Pengaruh Pertumbuhan Penjualan dan Likuiditas Terhadap Harga Saham PadaPerusahaanManufakturSektorAnekaInd utriYangTerdaftarDiBursa Efek Indonesia Periode2015-2019.

\section{B. METODOLOGI PENELITIAN}

Dalam penelitian ini menggunakan data sekunder yang berupa laporan keuangan perusahaan manufaktur sektor aneka industri. Selain itu, terdapat juga ringkasan saham yang diperoleh dari website Bursa Efek Indonesia. Penelitian ini dilakukan di Bursa Efek Indonesia (BEI) melalui situs www.idx.co.iddan gallery investasi BEI Universitas Tridinanti Palembang.Penulis menggunakan teknik pengumpulan data dengan dokumen yaitu dengan cara mengunduh laporan keuangan perusahaan manufaktur sektor aneka industry melalui website Bursa EfekIndonesia.

Populasi dalam penelitian ini berjumlah 24 perusahaan dan populasi ini merupakan perusahaan manufaktur sector aneka industry yang terdapat dalam Bursa Efek Indonesia atau Indonesian Stok Exchange (IDX). Berikut daftar populasi yang digunakan, yaitu:

1. Astra International Tbk.

2. Astra Otoparts Tbk.

3. Sepatu Bata Tbk.

4. Ever Shine Tex Tbk.

5. Goodyear Indonesia Tbk.

6. Gajah Tunggal Tbk.

7. Garuda Maintenance Facility Aero Asia Tbk.

8. Panasia Indo Resources Tbk.

9. Indomobil Sukses Internasional

10. Indo-Rama Synthetics Tbk.

11. Indospring Tbk. 
12. Sky Energy Indonesia Tbk.

13. KMI Wire \& Cable Tbk.

14. Steadfast Marine Tbk.

15. Multistrada Arah Sarana Tbk.

16. Asia Pacific Investama Tbk.

17. Pan Brothers Tbk.

18. Prima Alloy Steel Universal Tbk.

19. Sat Nusapersada Tbk.

20. Ricky Putra Globalindo Tbk.

21. Supreme Cable Manufacturing \& Commerce Tbk.

22. Selamat Sempurna Tbk.

23. Uni-charm Indonesia Tbk.

24. Voksel Electric Tbk.

Sampel penelitian ini adalah laporan tahunan perusahaan manufaktur sektor aneka industri yang terdaftar di Bursa Efek Indonesia tahun 2015-2019.Dalam penelitian ini digunakan metode nonprobability sampling. Berikut kriteria yang dibuat untuk memperoleh sampel adalah sebagai berikut:

1. Perusahaan manufaktur sektor aneka industri yang telah terdaftar di Bursa Efek Indonesia sebelum tanggal 31 Desember 2015 dan tidak delisting selama periode pengamatan 2015-2019.

2. Perusahaan manufaktur sektor aneka industri yang terdaftar dalam Bursa Efek Indonesia yang menerbitkan laporan keuangannya selama periode pengamatan pada tahun 2015- 2019 di website www.idx.co.iddengan lengkap.

3. Perusahaan yang selama periode penelitian data keuangannya mengalami peningkatan.

Teknik analisis data yang digunakan adalah kuantitatif dan statistik deskriptif. Disamping itu juga menggunakan uji asumsi klasik dan analisis linear berganda. Adapun hipotesis dalam penelitian ini adalah :

$\mathrm{H}_{1}$ : Diduga pertumbuhan penjualan secara parsial berpengaruh positif dan signifikan terhadap harga saham pada perusahaan manufaktur sektor aneka industri yang terdaftar pada Bursa Efek Indonesia periode 2015-2019
$\mathrm{H}_{2}$ : Diduga likuiditas secara parsial berpengaruh positif dan signifikan terhadap harga saham pada perusahaan manufaktur sector aneka industry yang terdaftar pada Bursa Efek Indonesia periode2015-2019

$\mathrm{H}_{3}$ : Diduga pertumbuhan penjualan dan likuiditas secara simultan berpengaruh positif dan signifikan terhadap harga saham pada perusahaan manufaktur sector aneka industry yang terdaftar pada Bursa Efek Indonesia periode 2015- 2019.

\section{HASIL DAN PEMBAHASAN}

\subsection{Analisis Pengaruh Pertumbuhan Penjualan Dan Current Ratio Terhadap Harga Saham Pada Perusahaan Manufaktur Sektor Aneka Industri SecaraParsial}

Berikut ini adalah tabel hasil pengujian hipotesis secara parsial yang telah dilakukan menggunakan program SPSS 17.0 :

Tabel 1.

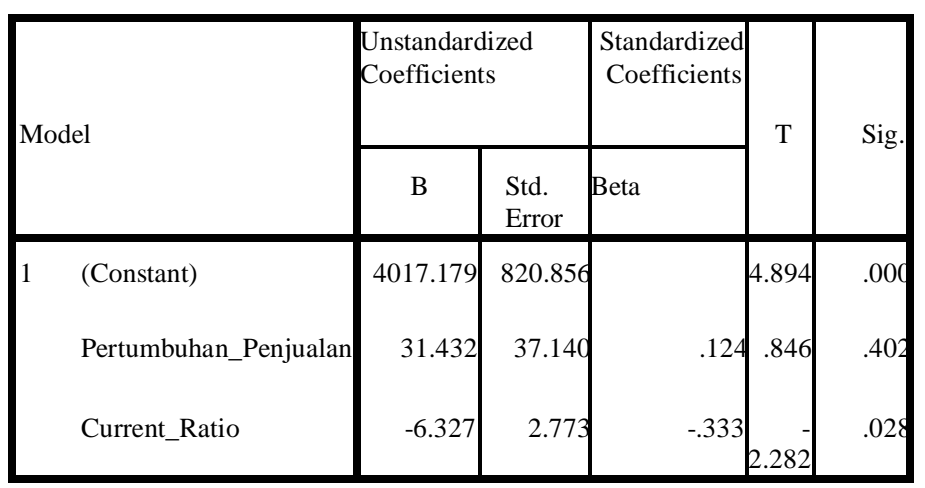

a. Dependent Variable: Harga_saham

Sumber: Hasil pengolahan data dengan program spss 17.0

Berdasarkan tabel diatas, diperoleh nilai regresi pertumbuhan penjualan sebesar31,432artinyasetiapperubahanpertum buhanpenjualansebesar 1\%,Harga Saham akan berubah sebesar Rp31,432.Sedangkan dari hasil uji $t$, diperoleh perbandingan $t$ hitung dengan $\mathrm{t}$ tabel adalah $\mathrm{t}$ hitung $<\mathrm{t}$ tabel $(0,846<2,018)$, sehingga $\mathrm{H} 0$ diterima dan $\mathrm{Ha}$ ditolak yang berarti bahwa pertumbuhan penjualan secara parsial tidak memiliki pengaruh yang signifikan terhadap harga 
saham pada perusahaan manufaktur sector aneka industri. Selain itu, dilihat nilai signifikansi uji $\mathrm{t}$ variabel pertumbuhan penjualan sebesar 0,402 . Karena nilai signifikansi $>$ dari $0,05(5 \%)$ taraf signifikansi adalah menerima $\mathrm{H} 0$ menolak $\mathrm{H}_{\mathrm{a}}$, maka keputusan yang diambil bahwa pertumbuhan penjualan tidak memiliki pengaruh terhadap harga saham pada perusahaan manufaktur sector aneka industri. Pertumbuhan penjualan tidak memiliki pengaruh yang signifikan terhadap harga saham mungkin dikarenakan fluktuasi penjualan selama tahun 2015-2019 yang menunjukan kondisi yang tidak stabil. 59,8\% nilai pertumbuhan penjualan pada sampel tidak memenuhi kriteria.

Nilai regresi current ratio sebesar 6,327 , artinya current ratio berpengaruh negatif terhadap harga saham. Jika current ratio mengalami kenaikan, maka harga saham akan mengalami penurunan. Sedangkan dari hasil uji t, diperoleh perbandingan $t$ hitung dengan $t_{\text {tabel }}$ adalah $t_{\text {hitung }}>\mathrm{t}_{\text {tabel }}(2,282>2,018)$, sehingga $\mathrm{H} 0$ ditolak dan $\mathrm{Ha}_{\mathrm{a}}$ diterima yang berarti bahwa current ratio secara parsial memiliki pengaruh negatif dan signifikan terhadap harga saham pada perusahaan manufaktur sektor aneka industri. Selain itu, dapat dilihat nilai signifikansi uji t variabel current ratio sebesar 0,028. Karena nilai signifikansi < dari $0,05(5 \%)$ taraf signifikansi adalah menolak $\mathrm{H} 0$ menerima $\mathrm{Ha}$, maka keputusan yang diambil bahwa current ratio memiliki pengaruh yang signifikan terhadap harga saham

\subsection{Analisis Pengaruh Pertumbuhan Penjualan Dan Current Ratio Terhadap Harga Saham Pada Perusahaan Manufaktur Sektor Aneka Industri SecaraSimultan}

Berikut ini adalah tabel hasil pengujian hipotesis secara simultan yang telah dilakukan menggunakan program SPSS17.0 : Tabel Hasil Uji F (Simultan)
TABEL.2

Tabel Annova

\begin{tabular}{|c|c|c|c|c|c|}
\hline Model & $\begin{array}{l}\text { Sum of } \\
\text { Squares }\end{array}$ & $\begin{array}{l}\mathrm{D} \\
\mathrm{f}\end{array}$ & $\begin{array}{c}\text { Mean } \\
\text { Square }\end{array}$ & $\mathrm{F}$ & Sig. \\
\hline $\begin{array}{c}\text { Regres } \\
\text { Sion }\end{array}$ & 4.503E7 & 2 & $2.252 \mathrm{E} 7$ & $\begin{array}{c}2.76 \\
7\end{array}$ & .074 \\
\hline $\begin{array}{l}\text { Residual } \\
\text { Total }\end{array}$ & $\begin{array}{l}3.418 \mathrm{E} 8 \\
3.868 \mathrm{E} 8\end{array}$ & $\begin{array}{l}42 \\
44\end{array}$ & $\begin{array}{r}8138194.8 \\
25\end{array}$ & & \\
\hline
\end{tabular}

a. Predictors: (Constant),

Current_Ratio,Pertumbuhan_Penjualan

b. Dependent Variable:Harga_saham

Sumber : hasil pengolahan data dengan program spss 17.0

Berdasarkan tabel diatas, diperoleh nilai $\mathrm{F}$ hitung dari hasil uji $\mathrm{F}$ sebesar 2,767 dengan nilai signifikansi sebesar 0,074 . Oleh karena $F_{\text {hitung }}<F_{\text {tabel }}(2,767<3,220)$ dan nilai signifikansi lebih besar dari taraf signifikansi 0,05 (5\%) maka keputusan yang diambil adalah menerima $\mathrm{H}_{0}$ dan menolak Ha sehingga dapat dinyatakan tidak terdapat pengaruh yang signifikan antara pertumbuhan penjualan dan current ratio terhadap harga saham pada perusahaan manufaktur sektor aneka industri.

Selain itu, dari hasil pengujian koefisien determinasi $R$ square diperoleh bahwa nilai koefisien determinasi dapat dilihat dari nilai tabel $R$ square yaitu sebesar 0,116 atau $11,6 \%$, artinya pengaruh pertumbuhan penjualan dan current ratio terhadap harga saham pada perusahaan manufaktur sektor aneka industri. sebesar $11,6 \%$ sedangkan sisanya sebesar $88,4 \%$ dipengaruhi oleh variabel lain yang tidak disebutkan dalam model penelitian ini.

\section{SIMPULAN DAN SARAN Simpulan}

Berdasarkan hasil pengujian hipotesis secara parsial (uji t statistik) dan secara simultan (uji F statistik) menunjukkan bahwa:

1. Variabel pertumbuhan penjualan secara parsial tidak memiliki pengaruh yang signifikan terhadap harga saham. Hasil yang diperoleh dari nilai signifikan sebesar $0,402 \quad(40,2 \%)$ yang berarti 
nilainya lebih besar dari taraf signifikansi sebesar 0,05 (5\%). Dengan demikian dapat disimpulkan bahwa pertumbuhan penjualan secara parsial tidak memiliki pengaruh yang signifikan terhadap harga saham pada perusahaan manufaktur sektor aneka industri yang terdaftar di Bursa Efek Indonesia periode2015-2019.

2. Variabel likuiditas (current ratio) memiliki pengaruh yang signifikan terhadap harga saham. Hasil yang diperoleh dari nilai signifikan sebesar $0,028(2,8 \%)$ yang berarti nilainya lebih kecil dari taraf signifikansi sebesar 0,05 (5\%). Dengan demikian dapat disimpulkan bahwa likuiditas (current ratio) secara parsial memiliki pengaruh yang signifikan terhadap harga saham pada perusahaan manufaktur sektor aneka industri yang terdaftar di Bursa Efek Indonesia periode 2015-2019.

3. Variabel pertumbuhan penjualan dan likuiditas (current ratio) secara simultan tidak memiliki pengaruh yang signifikan terhadap harga saham. Hasil yang diperoleh dari nilai signifikan sebesar $0,074(7,4 \%)$ yang berarti nilainya lebih besar dari taraf signifikansi sebesar 0,05 (5\%). Dengan demikian dapat disimpulkan bahwa pertumbuhan penjualan dan likuiditas (current ratio) secara simultan tidak memiliki pengaruh yang signifikan terhadap harga saham pada perusahaan manufaktur sektor aneka industry yang terdaftar di Bursa Efek Indonesia periode 2015-2019. Nilai Koefisien Determinasi ( $R$ square) sebesar 0,116 atau 11,6\%, artinya pengaruh pertumbuhan penjualan dan current ratio terhadap harga saham pada perusahaan manufaktur sektor aneka industri yang terdaftar di Bursa Efek Indonesia periode 2015-2019 sebesar $11,6 \%$ sedangkan sisanya sebesar $88,4 \%$ dipengaruhi oleh variabel lain yang tidak disebutkan dalam model penelitian ini.

\section{SARAN}

Berdasarkan dari hasil penelitian ini, maka saran yang dapat diberikan oleh penulis adalah sebagai berikut :
Bagi pengguna laporan keuangan, dalam pengambilan keputusan hendaknya tidak hanya melihat pertumbuhan penjualan dan rasio likuiditas (current ratio) saja. Perlu dipertimbangkan juga faktor-faktor lain dalam hubungannya mempengaruhi pergerakan harga saham seperti laba per saham, deviden per saham, nilai buku per saham, debt equity ratio, rasio likuiditas lainnyaseperti : quick ratio, cash ratio, cash turn over, inventory to net working capital dan rasio keuangan lainnya.

Bagi perusahaan manufaktur sektor aneka industri, diharapkan agar lebih memperhatikan kemampuan perusahaan dalam meningkatkan harga saham melalui berbagai cara terutama dalam pemanfaatan aktiva lancar dan meningkatkan penjualan dari tahun ke tahun serta meningkatkan produktivitas untuk memperoleh laba yang lebihtinggi.

Bagi peneliti selanjutnya, disarankan agar memperbanyak jumlah variabel faktor lain serta jumlah datanya agar penelitian selanjutnya dapat menjadi lebih tepat dan akurat.

\section{E. DAFTAR RUJUKAN}

Amstrong, Philip Kotler dan Gary. DasarDasar Pemasaran. Edisi Kesembilan.Jakarta: PT Index, 1997.

Bursa Efek Indonesia. n.d.http://www.idx.co.id/.

Darmawan,Arya."PengaruhRasioLikuiditas, SolvabilitasTerhadapHargaSaham pada Perusahaan pertambangan BEI ." (Jurnal Stei Ekonomi)2016.

Ekonomi, Fakultas. Pedoman Penulisan Skripsi dan Laporan Akhir. Palembang: Universitas Tridinanti Palembang, 2014.

Fahmi, Irham. Analisis Kinerja Keuangan, Cetakan ketiga. Bandung: Alfabeta,cv, 2014.

Rahasia Saham Dan Obligasi. Cetakan Kesatu. Bandung: Alfabeta, cv, 2013. Fakhrudin, Tjiptono Darmadji dan Hendy M.

Pasar Modal Di Indonesia Pendekatan Tanya Jawab. Jakarta: Salemba Empat, 2012. 
Ghozali, Imam. Aplikasinalisis Multivariate dengan Program SPSS. Edisi Keempat. Semarang: Badan Penerbit UNDIP, 2009.

Hadi,N.PasarModalAcuanTeoritisdanPrakti sInvestasidiInstrumenKeuangan Pasar Modal, Edisi Pertama. Yogyakarta: Graha Ilmu,2013.

Hasan, M. Iqbal. Pokok Pokok Materi Metodologi Penelitian Dan Aplikasinya. Jakarta: Ghalia Indonesia, 2012.

Jeany Clarensia, Sri Rahayu, Nur azizah. "Pengaruh Likuiditas, Solvabilitas, Profitabilitas, Pertumbuhan Penjualan dan kebijakan Deviden Terhadap Harga Saham (Studi Empirik pada Perusahaan Manufaktur yang Terdaftar diBursaEfekIndonesiaTahun20072010."(FakultasEkonomiUniversitas Budi Luhur) 25 - Nomor 1, Juni 2016(n.d.).

Kasmir. Analisis laporan Keuangan, Cetakan Kesembilan. Jakarta: PT RajaGrafindo persada, 2012.

Nandia, Umrotul Qilmi. "Pengaruh Pertumbuhan Penjualan, Operating Laverage dan Profitabilitas Terhadap Struktur Keuangan Pada Perusahaan Food And Beverage yang Terdaftar di BEI." 2016: 2.

Raghilia Amanah, Dwi Atmanto, Devi Farah Azizah. "Pengaruh Rasio Likuiditas dan Rasio Profitabilitas Terhadap Harga Saham (Studi pada Perusahaan IndeksLq45Periode2008-

2012)."(FakultasIlmuAdministrasiUni versitas Brawijaya)n.d.

Riyanto, Bambang. Dasar Dasar Pembelanjaan Perusahaan. Yogyakarta: BPFE- Yogyakarta, 2010. 